\title{
Sønderjylland 1928.
}

\section{Af Thade Petersen.}

\section{Grænsen.}

Tyskerne agiterer stadig mod Granseafgurelsen. Paa et Møde i Munkbrarup siger Pastor Schmidt, at det okonomiske Moment ogsaa vilde væle afgørende for Nordslesvigs Skabne (H. $\left.\left.{ }^{10} / 1\right) .^{*}\right)$ Selvistyrefolkene skal endog have gjort Forsog paa at danne en slesvigsk Brigade for at losrive Lantlet fra Danmark (11. $\% / \%$ ). Lei, Snogbæk, kiæever en ny Afstemning til Kongeaaen (I ${ }^{24} / 4$ ), og Advokat Poulsen siger i Tønder: Hrad vi oplever nu, er kun en Episode, der om Gud vil kun vil blive kort i Historien. (H $\left.{ }^{14} / 2.\right)$ Et ejendommeligt Udslag af denne Agitation var, at det viste sig, at en dansk Statsborger og Pensionist sad paa dansk Grund og agiterede mod den tyske Republik. (H ${ }^{18} / 2,23 / 2$.) Ikke mindst agiterer Tyskerne ud fra gkonomiske Forhold. (H ${ }^{24} / 2,{ }^{20}$ 3.) Den tyske "Aufwertung" gælder ikke danske Pengeinstitutter, Forsikringsselskaber og offentlige Korporationer. (H ${ }^{27} /{ }^{2}$.) Modsat Pastor Schmidt o. a. finder den tyske Digter Ernst Toller, at Afstemningen her foregik under saa lille Paavirkning som mulig (H. $\left.{ }^{16} / 2\right)$, og selv Ernst Schrøder synes at misbillige Grænseagitationen. (II ${ }^{10} / 2$. ) Ved et stort Ungdomsmode i Flensborg sagde en af Talerne: Græmsen ligger fast, og vi giver Afkald paa at rokke ved den. $\left(\mathrm{H}^{30}{ }^{\text {s. }}\right.$ ) Rigskansler Herm. Müller indskærper i Harrislev Pligterne i Forbindelse med Mindretalsordningen. ( $\mathrm{H} / 1 / 10)$.

Redskaber for Agitationen er Foreninger som Schlesw. Holst. Bund, der dog somme Steder sygner hen (H $5 / 1$ ), og i det hele er starkt aftagende. ( $\mathrm{H}^{12},{ }_{10}$.) Heller ikke den Presse, der staar i Agitationens Tjeneste, kan holde sig paa Højden. Hverken "Der Schleswig-Holsteiner" eller "Nordschleswig" har kunnet bære sig. (H $/ 1,25 / \%$.)

•) $\mathbf{H}=$ Hejnidal, H. A. = Haderslev Amtstidende, Av. $=$ Flensborg Avis, $\mathrm{L}=$ Nordslesvigsk Landbrugs- og Mejeritidende 1928. "Grænsevagten" anføres ikke sarskilt, da de enkelte Oplysninger der er saa vidt samlet om bestemte Emner, at de i Reglen er lette at finde. 
Nordschleswigscher Verhand hay dog fatat $9 \mathrm{ny}$ Lokalforeninger. ( $\mathrm{H}{ }^{10} 1.1$

Af $h$ is to iske Forhold vedrorende Grænsekampen kan navnes, at Slagordet "up ewig ungedeelt" findes $i$ en sang af Fysikus Neuber i Aabenraa 1841. For'st derefter skal det ret være kommen i Brug. ( $\mathrm{H}^{\left.10 / /_{1}\right)}$ H. P. Hanssen giver en skildring af cirnnsemblet i Flensborg ${ }^{12}{ }_{10} 1918$. (H. ${ }^{11 / 10}$.) Dr. Alnors Bog om thet slesvigske Suorgsmaal begynder at udkormme. (II ${ }^{1}$ 12.)

Giransestationen Padborg har efterhatanden medfort stor Tilfytuing og derfor Mangel paa Lejligheder (H 10/.) Den ny Banegarard toges i Brug ${ }^{1 / 8}$.

Den tysk-nationalistiske Agitation morl deu nol diske Universitetsuge i kiel misbilliges af "hichl.-

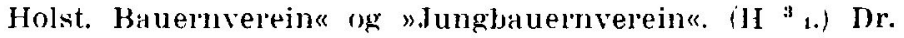
Schifferer overtog da atter Formandsposten i tiniversitetsselskithet $\left(\mathrm{H}^{24}{ }_{1,}{ }^{25}{ }_{1,},{ }^{24}{ }_{2}\right)$. Afholilelsen af tyen blev imidlertid senere ulsat til 1929 (II. ${ }^{10}$ z).

Imidlertid veltoges det at afholde en F feds $s$ a $y$ i Kiel den ${ }^{5}, 3\left(\right.$ H. $\left.{ }^{1+t / 3},{ }^{17} / 3\right)$ til Behandling af de okonomiske og kulturelle Forbindelser mellem Imanmark og Tyskland. (H. ${ }^{27}{ }_{3}$ ). Altyskerne raser indidlertid over, at ogsda H. 1'. Ifanssen er indbult, og Magistraten i Kiel tager sit Lofte orn at stille Raadhussalen til Raadighed tilbage. (H. " 4 . Modet afholdtes alligevel. (H. ${ }^{7}$,, $1 "$ ').

En Bestrablelse i lignende lietning var nogle Monler,

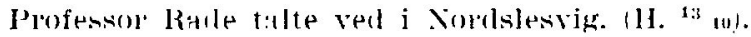

\section{Nationalt Liv ved Grænsen.}

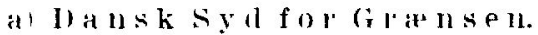

Til Valget den ${ }^{20}$ : urlsendte batale det danske og

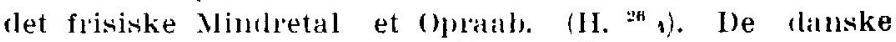

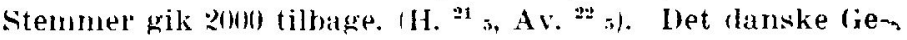
neralsekretariat i Flensborg venter dog, at de danske Arhejdele alligevel vil varpe mell til at mklave fri folkelig Urlvikling" og at "verme om rome folkelige Indretninger". (II. $z^{\prime}$ o). Pada den tyske Folkeforbundsliga blev der gjort opmarksom pad det danske Mindletals Anker mod den preussiske Mindretalsoming. Forhandlingerne var praget af gensidig Vilje til Folstanelse. (II. $\left.{ }^{21}{ }^{1}\right)$.

I)en danske II e n i ghe d i Flenshorg hat 3:4i Merlemmer. Del blev sidste Aar d $(3)$ t $2 \pi$ Born og konfirmeret 104. A $\mathrm{Av}^{15}$ 10, Af le sidsturynte val $61 \mathrm{for}$ storste Delen fra ten syllige Lel af Byen. (Ar. ${ }^{3}{ }_{4}$. 
For a I re ne fik omsider let til selv at bestemme deres Borns Skolegang. (H. $\left.{ }^{24} / 11,{ }^{30}, 11\right)$. Duborgskolen har 322 Elever, deraf 295 fra Syd for Græensen. Privatskolerne paa Lanclet har lidt Flemgang. (II. $\left.{ }^{14} / 5,{ }^{10} / 6\right)$. 11 af Duborgskolens Elever tog Eksamen svarende til dansk Praliminareksamen. (Av. $\left.{ }^{1}, 4\right)$. I Aventoft undervises nu nogle Born i Dansk uden for Skoletiden. Av. ${ }^{21} / \mathrm{s}$, II. ${ }^{21} / \mathrm{s}$ ).

Af danske $S$ a m m e noms ter skal navnes Aarsmodet i Flensborg den ${ }^{3}$ e. Det samlede 4000 Deltagere. (Av. ${ }^{3} / 6$, H. $\%$ ). Modet i Frøslev Polde (Av. " 7 . Ungdomsstarnet i Flensborg (Av. ${ }^{7}$ ) og det sonderjydske Kursus i Harreslev ${ }^{13}{ }^{10} /{ }^{10} /$. (Av. $\left.{ }^{20} / \theta\right)$.

Fra Flensborghus el udlaant $38,396 \mathrm{~B} ø \mathrm{~g}$ e $\mathrm{l}$. (Av. ${ }^{2 \pi}{ }^{5}$, $\left.{ }^{26} / 8\right)$.

"Der Schlewiger" er nu det eneste B la d i Flensborg, der ikke faar de offentlige kundgørelser. (Av. ${ }^{12}, 2$ ). Flensborg sygeplejeforening har godt 5.50 Medlemmer. (Av. ${ }^{21} / 3$ ).

b) Tysk syd for (ir a n en

De vk onomiske Forhold har vist sig at vare stalig daarligere syd for Griensen. "Bauernverein« truer med Vold. (H. $9 / 1$ ). Lit Bondemode i Rendsborg erklærer, at hvis Landbruget ikke faar sine "Insker opfyldt betragter det sig som retslus og fra ${ }^{1}{ }^{2}$ fritaget for alle Pligter. (II. ${ }^{14} / 1,{ }^{13}$ og $\left.{ }^{14}{ }_{1}\right) .{ }^{24}$, holdtes der Morde i 17 Byer. $\left(1 .^{30}{ }_{1}\right)$.

I Ilusum tankes anlagt et $\mathrm{s}$ vineksports $\mathrm{l}$ agteri. Nens Svinene i Dannark bringer 4546 tre netto pr Pund levende Vargt bringer de i Tyskland kun 37-38 (1).e. (II. ${ }^{20}$ \%). Det tyske Rige statter Provinsen med 2 Millioner" Mk. (H. " $/ 3$ ).

Ved Isted er der wet II a r $v * k$ mod schleppegrells Mindesnurrke. Ligeledes ved Helligba k norl Lajtnant Norlibergs. (H. $\left.{ }^{11} / \mathrm{T}\right)$.

ber findes nu $2 \pi$ nordslesvigske For'eninger', mest med selskabelig Virksomhed. (II. " ${ }^{*} / 7$ ).

c) Tysk i Nordslesvig.

Tyskerne er stadig sterke $i$ at stille $K \mathrm{l}^{\prime} \mathrm{a} v$. Den $\%$ a talte Pastor Schmialt i Folketinget. Han kravede tysk Selvstyre i skole og Kirke, rettede skjulte Angreb paa Politimesteren i Tondler og forlangte Liarerdommen fra Hojer undersøgt paa ny. (I. 3/4, //4). Deres ny Krav om Studenter- og Realeksamen blev afvist (H. ${ }_{3}{ }_{3}$ ) men teet for Jul fremsatte Pastor Schmidt endnu et Lovforslag om 
særiig tyske Skolekommissioner, tyskè højere Skoler og Tilskud til Privatskoler. (H. ${ }^{20} / 12$ ). I det hele søger Tyskerne at is ol ere sig. $\left(\mathrm{H}^{3}{ }^{3 / 8}\right)$. I god Samklang med dette er det, naar Ernst Schrøder vil føre den nationale Kamp ind $\mathbf{i}$ et bedre Spor ved at forny den tyske Folkelighed og kræve en ny Grænseafgørelse. (H. ${ }^{10} / 1$ ).

Den tyske Vælgerforenings $K$ ont or i Tønder arbejder ivrig. (H. ${ }^{13} / 1$ ). Schl.-Holst.-Bund har . oprettet et Gransebibliotek, hvor al Litteratur vedrørende Gransespørgsmaalet findes. (H. $\left.{ }^{31} / 1\right)$. Tysk Ungdomisarbejde skal have vundet mange tabte gamle tilbage. (H. 1/2). I Tønder er et tysk Hus indrettet. (H. ${ }^{8} / 2$ ). Krigerforeningerne har 1160 Medlemmer i Nordslesvig. (II. ${ }^{12} / 8$ ).

O k o n om is k bæres det tyske Arbejde væsentligt ved Støtte Syd fra. Ved Nytaar 28 var der $18 \gg F$ a d d e rskabsforhold«. (H. $\left.{ }^{3} / 1\right)$. En enkelte Organisation samlede i Løbet af kort Tid ca. 300,000 Mk. til Skoler i Nordslesvig, (H. ${ }^{27} / 1$ ), Skolerne i Slesvig-Holsten 81,000 Mk. (H. ${ }^{28} / 2$ ), "Verein f. d. Deutschtum i. Auslande 2 Millioner Medlemmer og over 2 Millioner Mk. Indtægt. Den indsamlede i Februar 43,017 Mk. til tysk højere Skolevasen i Nordslesvig. (H. ${ }^{30} / 5$ ). I Fjolde Sogn alene lovede man at skaffe 1000 Mk. til tysk kirkeligt Arbejde i Nordslesvig. (H. $\left.{ }^{18} / 8\right)$. Foreningen f. Tyskhed i Udlandet har 15 Filialer og 1474 Skoleafdelinger. Dens sl.-holst. Afdeling har i 1927 skaffet 103,000 Mk. til nordsl. Kulturarbejde. (H. ${ }^{27} / 9$ ). Tyskerne i Sønderborg fik alene fra Kiel 53,000 Mk. (H. ${ }^{10} / 11$ ). Men de slaar ogsaa ivrigt paa Hvervetrommen. $\left({ }^{29} / 6\right)$.

Imidlertid er de ikke helt fri for indre Splid. Det 3. Nummer af "Die Königsau" angriber Pastor Schmidt og den tyske Vælgerforening (H. ${ }^{10} / 1$ ), og Dr. Kardel maatte fratræde "Neue Tondernsche Zeitung", fordi hans mere moderate Synspunkter ikke kunde komme til Orde i deres Fællesblad. (H. ${ }^{10} / 12$ ).

Tyskerne begynder at nære Bekymringer med Hensyn til deres Fremtid. "N. Tond. Zeitg." skriver, at hvis Tyskerne ikke kan skaffe Jord til deres Ungdom, maa de om faa Aar betragte Kampen som tabt, og Koch (før paa Mandbjerg) skriver, at den tyske Befolkning er dybt nedslaaet. (H. ${ }^{11} / 1$, H. A. $\left.{ }^{12} / 1\right)$. En Opfordring til tyske Unge til at studere i København er i Virkeligheden udsprunget af samme Følelse. (H. ${ }^{12} / 1$ ). Da Friherre Kerckering solgte 
en Ejendom paa 30 ha i Horslund til en dansk Mand overfaldt de tyske Blade ham (H. 23/1) og Bauernverein opfordrede ham til at købe en anden. (H. ${ }^{6 / 2}$ ). De danske Biblioteker betragter de ogsaa som en Fare. (II. ${ }^{24} / 2$ ). De frygter $i$ det hele for at blive tilintetgjort. (H. ${ }^{25} / 0$ ).

Privatskoler har Tyskerne i $192 \%$ oprettet i Hokkerup, Bjerndrup og Rødding og desuden indviet ny Skolebygninger i Tinglev og Sdr. Vilstrup. (H. $\% / 1)$. Den tyske Skoleforening i Tinglev vil stille ny Krav til Folketinget under Henvisning til det preussiske Skolereskript (H. ${ }^{4 / 2}$ ) men faar Afslag fra Ministeriet. (II. ${ }^{14} / 6$ ). Tinglev Højskole havde 36 Elever til Sommeren og var dermed optaget. (H. ${ }^{25} / 2$ ). ${ }^{26 / 2}$ indriedes Privatskolen i Bjerndrup (H. ${ }^{28} / 2$ ). ${ }^{6} / 5$ den i Rødding (H. ${ }^{7} / \%$ ) og $3 / 6$ en i Sønderhav. (H. ${ }^{8 / 8}$ ). I Løjt søgte tyske Medlemmer af Skolekommissionen at hindre Ungrlomsforeningen i at bruge Skolens Gymmastiksal til et Møde. (H. $\left.{ }^{17}, 10\right)$.

Ogsaa paa $\mathrm{k}$ i r kens Onraade udfolder Tyskerne en hidsig Agitation. Der er nu 41 Kirker med delvis tysk Gudstjeneste mod 25 i 1921. (H. ${ }^{25} / 1$ ). Desuden har Fremmedmenighederne 4 Pr'tester med Kredse i 26 Sogne. (H. 21/5). I November 28 havde de 24 Menigheder og holdt maanedlig 96 Gudstjenester og Møder paa Landet. (H. 9/.1). Ogsaa $i$ det Stykke er de fordringsfulde og vil have Lov til uden videre at holde tyske Gudstjenester efter Behov i Kirkerne og lade Praster fra Tyskland prodike ved dem, samt at i Byerne kun de tyske Menighedsraadsmedlemnier skal have Lor til at indstille Præster for den tyske Menighed. (H. ${ }^{* 6}$ ). Pastor Horstmann foreslaar at skabe en Organisation for 1) Enkeltmenigherler, 2) for hele Kirkesanifundet. (H. ${ }^{12}$ i1).

De tyske Ung dom f oreninger har 1481 Medlemner. (H. $\left.{ }^{12}, 12\right)$. De har Ungdomsherberger i Aabenrad, Broager, Haderslev, Hejsager Strand, Høruphar, Knivsbjerg, Løgumkloster, Nørborg, Sønderborg, Tingler og Tøuder. Det i Høruphar er dog ophavet igen. (H. ${ }^{10}{ }_{7}$ ). Den tyske Studenterforening i København, der for 4 Aar siden begyndte med 5 Medlemmer, har nu 30. (H. ${ }^{14}$ 's). 180 Brrn fra Nordslesvig var i Besøg i Tyskland. (H. ${ }^{15} / \mathrm{s}$ ).

Det tyske Bibliotek i Aabenrat faar sit Bidrag fra Byen forhøjet fra 400 til $1000 \mathrm{Kroner}$ ( $\mathrm{H}^{{ }^{17}}{ }^{\mathbf{2}}$ ). Radiostationen i Flenshorg venter Tyskerne sig meget af. $\left(H .{ }^{7} /\right.$ r. $)$

$\emptyset \mathrm{konomisk}$ vilke de gerne oprette Forbindelse med Tyskland. (H. $/ 2,4 / 10)$. Ogsaa fra Nordslesvig er der 
die tyske Lambuaxh merl i Droftelsen af et stort slagteri i slesvig (II. $\left.{ }^{N}{ }_{6}\right)$, og Landbrugskamet i Kiel har 4 Tillidsmand i Nordslesvig, som skal hjolpe Tyskere med deres Kvarghandel syal paa. (H. ${ }^{11 / 12}$ ).

I) enonstrat ioner kan Tyskerne ikke godt lade varle mel. I Tonder laverle en cinglomsforening et demonstrativt optog (II. ${ }_{2}$ ) $O g$ besvarede sig endala over, at det blev forhindret. (H. ${ }^{5}$ ). I Bylderup lavede de Skattestrejke for at fremtvinge ophavelsen af en Larerplanls. (II. " ${ }_{10,}$ 1" $10,{ }^{17 /}{ }_{10)}$ ).

Thomas Sichmidt fra IIoviund talte pal Knivsbjerg

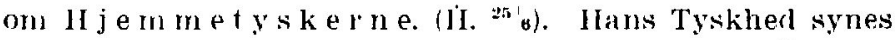
dog ikke at vale symderlig andelig bestemt. (II. ${ }^{29}$ s).

(b) I) a ltsk i Noraslesvig.

Selv et Bhal som "Deutsche 'Tageszeitung" anerkenrler, at den danske legrering anstantigt har holdt sine Loftel til Nomdslesvig. (II. 1:3 1$)$.

De danske () ga a nimationer ubviles med et "Wansk Kontor" i Tomder (II: " 1). Sprogforeningen havdo verl Aarsmshet fokx Medlemmer, Skoleforenimgen 12,jo (11. $\left.{ }^{2}{ }^{2},{ }^{7}{ }_{2},{ }^{2}{ }_{\theta}\right)$. Glarleligt var det, at Sprogforeningen i

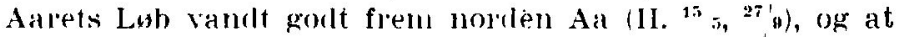
et Brand-Folsiklingsselskah skankecte de nationale Foreninger :25,0no Kr. (H. ${ }^{11}$ 7), heskarmmente derimod, at en Thybo jaa de danske ITngdomsmoningers Aarsmode ankede over, at iler of redes for meget pas sonderjyland.

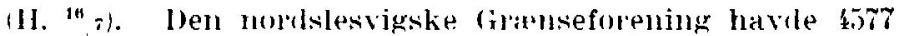
Medlemmer. (II. "3). I det hele har Foreningen 4:000).

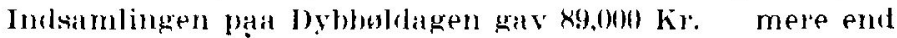
nogensincle for. (II. ${ }^{22}$, $)$.

Afstemnings festerne var starkt besingt og Ung-

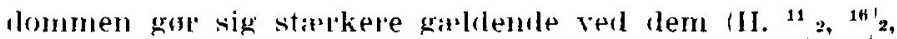

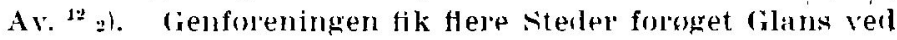

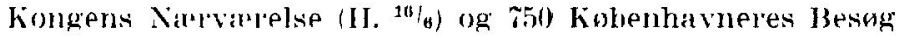

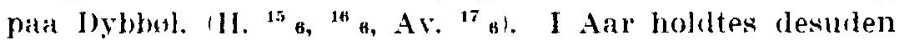

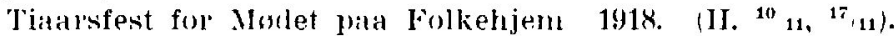
1 11 fylate Fumlev Sangforening jo Aar. (Av. 15 11, H. " ${ }_{11}$ ).

()nbygningen til L, a nas a l kiv i Tunder vil koste $50,000 \mathrm{Kr}$. (II. " $" \%$. Fit Lovforslag om det flemsattes. (II. $21 ; 1$.

" 1" " holall I)ansk historisk Follesforening sit Aajsmorle j sonderborg. Historisk samf. f. Smurlelj, holdt

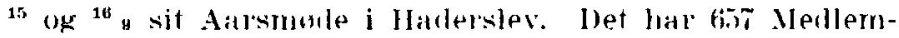


mer. (II. $\left.{ }^{17}{ }_{H}\right)$. I nogle Artikler giver H. P. Ilanssen Dagbogsnotitser fra Genforeningstiden. (H. ${ }^{23},{ }^{30}{ }_{11}, 3,3,14 / 1 z$ ). Bibliotekerne har ${ }^{2 \times}$ faret $\left.\tau 6,0\right) 29$ Kr. i statstilskud. (H. 16/10).

Forsam lingshus er der19:0 hygget eller indviet i Logumkloster (H. ${ }^{10} /{ }_{1}$, Ar. ${ }^{17},{ }_{1}$ ) Padborg (H. ${ }^{14}, 7,4 / 8$, 20/A og Lydersholm. (H. $\left.{ }^{17} /{ }_{2}\right)$. Haderslev Højskoleh jem genindviedes. (II. ${ }^{21 / 3},{ }^{21}$ ). I Tinglev stemite et Flertal for Spiritusbevilling til 'Tinglevhus. (I. ${ }^{21},{ }^{12}$ ). Der er nu 20 Forsamlingshuse i Granseegnen, mens der for Krigen kun var 6. (H. $\left.{ }^{25} / \theta\right)$. Foreningen for national hunst hal skarnket 7 -8 Billeder til hvelt Forsamlingshus i Nordslesvig. (II. $30 / 1$ ).

I drat t e n drives ivrigt. Iner udrleltes i oktober Kvartal 192\% 12 Guld-, 9 Salv- og $2 \pi$ i3 Broncemarker for Idrat i sonderjylland. (H. " $/ 1$ ). Sonderjydsk Idrustsforfning begyndte 1903 med 7 Kredse i lladlersles Vesteramt, havde 1921 61, 1927 119 Kredse med 2855 Gymuaster. (H. 10, 12/s). Gymnastikforeningerne i Hadelslev (Hsteramt gav 22 stor falles Opvisuing. (H. ${ }^{2 ! 3}$ 1). Haderslev Fodboldhold naaede op i Mesterrakken. (I1, 25'6). Hoverlbegivenheden val dog Skytte- og (yymnastikstavnet paa I)ybbrl. (II." $=0$ og 7 ).

L'ng doms a rbejal skol i Aar et nyt Skud idet der i Aabenraa Amt sattes et saakaldt praktisk Ungdomsarbejole i Gang. (II. '1). I Jumi val ca. 200 unge Mand og 150 unge Piger i Gang mea (let. (II. 12/6). Det aldre Ungdonsarbejcle med hovedsagelig a andelig Paavirkning kritiseredes starkt (H. A. ${ }^{\prime}$ ) og drofterles par Lngdomsstavnet i Haderslev. (II. ${ }^{y} / 1$ ). Iøvigt gik det $\sin$ javne Gang og samlede mange. (H. ${ }^{16},{ }^{26 / 4}, 7 / 7,{ }^{24} / 4$, Av. ${ }^{2 \mathrm{H} / 8} / 8$ ). Efterskolen i Rens havde 39 Elever til Vinteren. (Av. ${ }^{31 / 10}$ ).

Der er i Sonderjylland 240 gule $\$$ p e j d e r e, 88 gronne og 350. F. D. F. (II. $\% / 2$ ). Ved Gravenshoved afholdtes en stor Spejuerlejl. (H. $\left.{ }^{12 / 7},{ }^{16 / 7}\right)$.

Af $B$ esog her skal navnes to $_{0}$ Kobenhavnere paa Dybbol, (II. 15/6) I)ansk-Amerikanere paa Dybhol, (H. 13/s) Fynske Husmind pad Rejse. (H. ${ }^{24 / 7}$ ). Helfä val den nordsl. Handboforening i Fsbjerg. (II. ${ }^{12}$ 7).

Af støre faststaaende Morler skal novnes det kirkelige Mode i Vedsted (H. $\%$ ) og Efteraarsmodet i Slogsherredhus. (Av. ${ }^{10 / \%}$ ).

Landevarnet har i $192 \pi$ ydet 390 Laan paa $1,063,750 \mathrm{Kr}$. og varnet 14,391 ha. (I1. ${ }^{6} \mathrm{og}{ }_{3}{ }_{3}$ ). Vogelgesang 
paastaar, at han ikke kaber Gaarde, han ikke har belaant. (H. ${ }^{30}{ }_{1}$ ).

Dansk nationalt Arbejde styrkedes ved samling af Kræfterne, idet Sprog-, Skole- og Grænseforeningen enes om at virke i Farlesskab. (H. ${ }^{21}$ og $\left.{ }^{23} / 1\right)$.

\section{Politik.}

Den ${ }^{14}$ afholdtes $\mathrm{V}$ a $\mathrm{g}$ g til Landstinget. Tyskerne fik ved det $14,6 \%$ af Stemmerne $\bmod 15,4$ i 1926 . (II. ${ }^{15} / 4$ ). Deres faa Valgmiends Stemmel kobte socialdemokrateme morl Lafter vedrorende Skoleforholdene. (H. ${ }^{24 / 9}$ og ${ }^{25} / \mathrm{s}$ ). Leiniendene havde Listeforbund med Tyskerne i nogle hiredse. (H. $\left.{ }^{10}{ }_{8,}{ }^{3},{ }^{10},{ }^{13},{ }^{13} / \mu\right)$.

Mel'e Røre end Valget voldte "Bevagelserne«. Corn. Petersens selvstyrebevagelse gjorde endnu en sidste Krampetrakning, idet han folgerves vilde prove par at inddrage sine $S$. $O$. $S$. Sedler. (H. ${ }^{11}$ og ${ }^{15}(;)$. lit Par Maaneder senere viste det sig, at S. (). S. Kassen var forsvunden. (II. 30/7). Corn. Petersens Nervesystem brod sammen (H. ${ }^{10 / 9}$ ), og han maatte senere indlipgges pat en Sindssygeanstalt.

Saa meget starkere Fart tog nu den Bevagelse, der fik Navn efter Gaardejer L e i i snoghak. I Slagt med (len var Nustrupbevægelsen (H. ${ }^{20},{ }^{21} / 3$ ) og Hoptrupbevargelsen (II. ${ }^{27}, 3$ ), (ler dog kun fik mindre Betydning. Skont cle fik mange Danske med var Lederne i Leihevargelsen Tyskere (H. $\left.{ }^{13}{ }^{4},{ }^{12} / 5,{ }^{22} / 6,{ }^{31 /} /{ }^{1}{ }^{1}\right)$, hvis Formaal var en Flytling af den skonomiske Gianse (H. $2 / 5,14 / 4,16,4)$. Bevaxgelsen søgte $i$ det hele at vinde Folk ved okonomiske Fantasterier, (H. $\left.{ }^{17}{ }^{4}\right)$. Dens mere eller mindre urimelige Krav sammenfatterle de omsider paa en Plakat, der en Nat blev klaphet op rundt om i Landet. $\left(\mathrm{H},{ }^{21}{ }_{4},{ }^{24} / 4,1 / 5\right)$. Leis Program skal have faaet 18,000 Underskrifter. (H. ${ }^{3} / 5$ ). Callo modbeviser Leis mørke Skildringer. Af Regeringen faar Lei Afslag paa sine Krav. (H. ${ }^{5}$ ). Der paastaas, at han faar Penge Syd fra. (H. ${ }^{18} / 3,{ }^{22}$ s). Det nagter han. (H. $\left.{ }^{21}{ }^{3},{ }^{26}{ }^{5}\right)$. Tinglevbevagelsen tager Afstand fra ham. $\left({ }^{14} / 4,{ }^{21},{ }^{7}, 5\right)$. Socialdemokraterne ogsaa. (H. $\left.{ }^{*}\right)$. Paa et stort Møde i Gram 24/5 holdt Statsminister Madsen-Mygdal Opgor med Lei og tog dermed vasentlig Livet af Bevargelsen, der snart ebbede ud, selv om den endnu prøvede piad at rore sig (II. ${ }^{26}$ o), og Lei endog tik en Samtale med Kongen, der dog kun henviste ham til Regering og Rigsdag. (H. $\left.{ }^{15 / 6}\right)$. 
For ved hjesyn at skaffe sig nærmere kendskab til. Forhold hernede hesøgte Indenrigsminister Kragh forskellige Egne i Dagene efter $\operatorname{den}^{18 / 5}$.

\section{Samfundsforhold.}

Byernes I n d b y g g e rant a l var ved Twllingen i November i 1928 Haderslev 14,481, Aabenraa 8,691, Sonderborg 10,271, Tonder 5,650. (H. ${ }^{28}, 11,4 / 12,{ }^{8 / 12}$ ). I Tonder Amt fødtes 1927 925 Børn; der døde 406 Menmesker, deraf 220 over 65 Aar. Dødelighedsprocenten var i Tønder og Flapkkerne 11,3, paa Landet 10,4. Edrueligheden er i god Fremgang. (Av. ${ }^{20}$ ). (Medicinalber. f. Tonder Amits Lazgekreds 1927.) 1921 fandtes i Sonderj. 14,297 Personer fwilt norden Aa, mens der der fandtes 19,167 født i Sønderjylland. Her fandtes 16,615 fodt i Tyskland. (II. ${ }^{13}, 1$ ).

U d s tykningen fremmedes videre. laa kiding solgtes 4 Lodder, paa (irøngroft 9, i (1ster Aabslling 4, fra IJovgaard 5, (H. $\left.{ }^{24},{ }^{1}{ }^{2},{ }^{2}{ }^{2}\right)$, i Froslev el der $2 \% 0$ Tonder

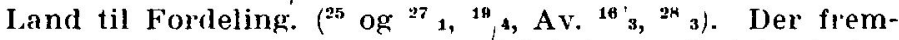
sattes enclnu et Lovforslag om 4 Millioner til Iddstykning par folkefattige Egne. (H. $\left.{ }^{7}{ }_{3}\right) .{ }^{27}{ }_{2 \times}$ opretterles 67 selvstandige Ilusmandsbrug (II. ${ }^{26}$ ), mens der i 1929 state omtrent 300 ha til Cdstykning. (H. $\left.{ }^{25}{ }_{6}^{6}\right)$. Til (oprettelse af (iaarde blev der 1928 kun $300,000 \mathrm{Kr}$. (II. ${ }^{2 \mathrm{~N}}$;).

Ved Nytaar 28 var der 3305 arbejdslose. (H. ¿il II. 1. 12' ${ }_{1}$ ). Antallet sank jarnt til 2596 midt i Marts. (II. ${ }^{17}{ }_{3}$ ). Mirlt i April var der i Sl.-Holst. 104,95.3 mod 61,36ix i hele Danamrk. (II. ${ }^{10}$, ). Enchu midt om sommeren var der i Nordsl. ca. 1200. $\left({ }^{14}{ }^{\prime},{ }^{25} \mathrm{~s}\right)$. I Haderslev hlev der ved et 10 $\%$ Tilskud sat Arbejde i (rang for $400,000 \mathrm{Kr}$. (II. A. ${ }^{15}$ \%). Arhejdsanvisningskontoret i Hatlerslev anviste ${ }^{2 \pi}$ is Arbejde til $1 \times 38$ Personer. (H. ${ }^{2}{ }_{6}$ ).

Paa Borneforsorgens Omratle el at narne, at der dannedes en Virperaudsforening i Aabenrat Amt. (II. ${ }^{2}(2)$. Irelsehjem husede 308 Børn. (II. ${ }^{23}{ }_{3},{ }^{20 / 8}$ ).

Tuberkulosen hierger slemt. Mens ler i hele Landet er 26,9 Tuberkuloseinvaliditetskendelsel for hver 10,000 sygekassemedlemmer er der i Hadersler 44,1, Aabenraa 51,8, sonderborg 21,7 og Tonder 16,6. Paa Landet i Amterne henholdsvis $43,8,37,2,38,8$ og 44,3 . (II. ${ }^{21} / \mathrm{m}$ ). Til Bekipmpelse af den fortsattes nu Tuberkulosehospitalet i Aaßenraa (II. ${ }^{18 / 1},{ }^{20} / 3$ ), og der oprettedes Tuberkulosestationer i alle Amter. (H. $\left.{ }^{26}{ }^{4}, A v \cdot{ }^{13},{ }^{10}\right)$.

Et Folkekskken, der oprettedes i Hadersley tik 
ingen synderlig Sogning (II. ${ }^{4}$ ) og maatte smart standse.

Kvindeforeningen har Fremgang. (H. 14 $\left.{ }^{5}\right)$. Invalideforeningen har faaet Afslag par sine Resolutioner fra i Fjor. (H. $\left.{ }^{22}, 5\right)$. Sygek asserne mnskel at heholde de bemidlede Medlemmer. (H. ${ }^{12}$;). Centralforeningen omfatter 105 Sygekasser med 72,604 Medlemmer i Nordslesvig. (H. ${ }^{27}, \%$ ). Den samvirkende smolerj. Sygeplejeforening omfatter $2 y$ Foreninger. (H. ${ }^{1}$ s) Augustenborg slot kan for 2,1 Million $\mathrm{Kr}$. omdannes til llospital for 4.50 sindssyge. (H. ${ }^{25}{ }_{k}$ ). Sygdomspromillen var i August 3,1 i Ribe Amt $\bmod 6,7$ i Haderslev 7,1 i Aabenraa og sonderborg og 4,9 i Tonder Arrt. (H. ${ }^{3}$ 10). En Bl in d e hasar i Aahenraa gav over $5000 \mathrm{Kr}$. (Over'skurl. (H. ${ }^{12}{ }_{11}$ ).

Af $\mathrm{L}$ e j $\mathrm{l}$ i g h e d e r var der ${ }^{1} 1127$ ledige: 14 i Haderslev, 32 i Aabenraa, 34 i Tonder, 8 i llalvdelen af Sonderborg. (H. ${ }^{25}{ }^{\text {}) . ~ A f ~ n y ~ L e j l i g h e d e r ~ b y g g e d e s ~}{ }^{27}{ }_{2 \pi}$ i Haderslev 26, i sønderborg 51, i Aabenra 31, i Tonder 2. (II. ${ }^{22}$ '12).

Det viser sig helt usandsynligt at finte l) rikke$\mathrm{v}$ a $\mathrm{nd}$ i Marsken. (H. ${ }^{412,} \mathrm{Av},{ }^{{ }^{0}}{ }_{12}$ ).

Den alsiske B r a n d f orsikring har ca. 6000 Medlemmer med $6 \tau$ $6 x$ Millioner Forsikringssum. Den er stiftet i Ketting 1Kis8. (II. ${ }^{9}{ }_{3},{ }^{27}$ s). I)en nor(ustslesvigske Brandforsikring for Bygninger er stiftet 1xi\%. I)ens Forsikringsmatsse er. 116 Millioner. (II. 3'1). Brandskaderne menes ikke at vape hyppigere her end pata andre Egne. (II. $\left.{ }^{11}{ }_{1}\right)$.

\section{Erhverv og Okonomi.}

Darmmingen til sild hal i hoj (alad flemmet.sil i a flejuingen, isipr par Norlsiden. Det kommer i nogen Grad ogsia den danske Del af Kysten tilgorle. I Nirtheden af Dammingen el Aflejlingen 75 ) 100 cm tyk. (Av. ${ }^{18}$, H. ${ }^{2: 3}:$. Mere og hurtigere end ved Landvindingen urviles eller rettere forberlres Landbrugets Aleal ved $A$ fvandingen. Det store Foretagencle ved Tonder skridel jasnt fremal. (H. ${ }^{4},{ }^{25} 7$ ).

Inens tages andre strakninger i Thlsigt eller siptes i ciang, saaledes 610 ha i sulsted, Bredebro og Visby (H. 1" $\left.{ }_{1}\right)$, mellem Refsu og stavedbro (II. ${ }^{19}{ }_{1}$ ) 45 ha ved N. (molev (II. ${ }^{*}$ ), og ved stolbro Bark og Tarming Malle. (H. $18.2,{ }^{17} / 2$ ). Ved Rojbul Birk er 125 ha af vandet for $89000 \mathrm{Kr}$. (11. "* "i). Til stotte for slige (irundforberlyingel kan 4 Millioner $\mathrm{Kr}$. anventes i Lan pata indtil $4000 \mathrm{Kr}$. (I1. $25 / 4$ ).

Af le byggede I) i $g$ e l blev Juvediget pala Immo som 
det sidste fardigt. (Av. ${ }^{10}, 7$, I. ${ }^{2 *} / 7$ ). Havnebydiget derovre led slemt, den ${ }^{2: 3}, 11$ ligesom ogsaa Rejshydiget men de holdt dog. (II. ${ }^{26} / 11$ ) Juvre Enge har ved Inddigningen rundet meget i Godhed. (H. ${ }^{2 \theta_{(8)}}$ ).

Hygum og (Omegns P la $\mathrm{n}$ t $\mathrm{n}$ ing $\mathrm{s}$ forening har i 1927 leveret 52,029 Løvtrier og 51,250 Naaletraer til 113 Modtager'e (If. $9 / 1$ ), og i Tønder Amt har I’lantningsselskabet Sønderjylland tilplantet ca. 20) Tøncler Iand og Hedeselskabet dannet 20) Plantager paa tilsammen $\delta(x)$ Tønder Land siden Genforeningen. Desuden er Tonder By i Fard med at tilpirinte 120 T(l., Land paa Abild Hede. (Av. ${ }^{27}{ }_{4}$ ). I Anbenraa og Sønderborg Amiter har Smaaskovsforeningen nu 217 Medlemmer nod 212 i 19:7 (Av. $\left.{ }^{27} / 4\right)$. Norre Rangstrup Ilerreds Plantuingsforening har uddelt ca. 170,00() Træer og køht Branderup Plantage (H. ${ }^{3 /} / \mathbf{s}$ ).

somlerjyllands Landejentomme v u rderedes i $19 \%$; til 487 Millioner $\mathrm{K} \mathrm{r}$. Der hviler 304 Millioner Gald paa dern. 19,2 pCt. af Ejendommene er vel gixldfri, men Gixldsprocenten er ellers $62 .\left(H .{ }^{3}, 7\right) .1927$ vurderedes de til $4 \times, 6$ Millioner (II. ${ }^{*}$ ). Alle faste Ejendomme er vurderet til

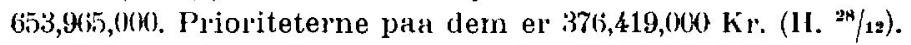

Af grodeenhederne er fra 290 Mill. i $19 \% 0$ steget til i2x Mill. i 1926, Melkemengden pr. Ko fl'a 142: $\mathrm{kg}$ til 2\%1.5, svinebestanden er vokset med $1 \times 7$ pCt., Malkekøerne med $27 \%$, Holnkvaget ialt med $13 \%$. (II. A. ${ }^{14} / 7$ ). Kuernes Antal voksede 1927 med 209 i Iladerslev, 849 i Aabenraa, 497 i sonderborg og 1069 i Tonder Amt (I. $\left.{ }^{30}{ }^{\prime}\right)$. Malkemangden steg fra $26-27$ med $l i-\tau \%$. Den er pr. Ko 2 (titio kg. )I. 1(j) d. 12. og 4.59).

liegnskaberne viser nu ogsaa nogen fremgang i frorrentuingsprocenten. Den var paa Roddingegnen $2,5 \bmod 1,9$ og 1,2 de to foregaaende Aar. (H. $\left.{ }^{5} / 10,{ }^{15} / 10\right)$. Paa Aabentaaegnen er den steget med 0,9 sillen 19:7, paa Hadersleveguen er den 2,6 mod 0,6 i F jor. (II. ${ }^{27} / 11$ ). I Agerskov Sogn havile 54 Formuefremgang, 35 Balunce, 109 Tilbagegallg (H. ${ }^{14}{ }^{3}$ ).

M e je rierne lider under det at vie for smaa. Kun $35 \%$ af dem hernede har over 2 Millioner $\mathrm{kg}$ Maxlk, mens der i Landet som Ilelhed er 76 \% over demne Granse (I. S. 478) 90 \% af dem har inillertid Mixlkebedommelse og $80 \%$ Koleanlarg (L S. 4.59). I Sommeren 1927 var mange af dem paa de vestlige strog af klimatiske cirunde udsat for at miste I.urma'l'ket, samtilig med at sonderborg Amt ved 
Forsøgslaboratoriet blev det bedste i hele Landet og i 1928 endog slog sin egen Rekord (L. S. 27) og naaede en Højde der ikke tidligere er naaet i noget $\Lambda \mathrm{mt}$. ( $\left.\mathrm{H} .{ }^{18} / 2\right)$. Ved den jydske Mejeriudstilling blev Sønderborg Amt Nr. 3, Haderslev Nr. 10, Aabenraa Nr. $14 \mathrm{og}$ Tønder Nr. 16 (H. ${ }^{30} / 3$ ). Ved Forsøgslaboratoriets Bedømmelse kom $10 \%$ af alle Mejerier i bedste Tredjedel. Af disse er igen 13,5 \% sønderjydske (H. $\left.{ }^{11} / 4\right)$. I 1928 kom Mejerierne i Tønder $\Lambda \mathrm{mt}$ dog godt md og fik paa den sønderj. Mejeriudstilling Plads ved Siden af de andre Amter (H. $8 / 6) .64 \%$ af Mejerierne afregnede i 1927 efter Fed tprocent $\bmod 46 \%$ i hele Landet. Broager Mejeri gjorde det allerede 1887, vistnok det allerførste (H. $\left.{ }^{11} / 10\right)$. I Januar nedsatte den sønderjydske Mejerifor'ening et Noteringsudvalg og satte Notering for Detailsalg (H. $\left.{ }^{16} / 1\right)$. Mange Mejerier har faaet starkt forøget Mælkemængde. Skrave $10 \%$ i $1927\left(\mathrm{H} .{ }^{10} / 1\right)$. Toftlund har 26/27 6,7 Mill. Pund $\bmod 3$ Mill. 20/21 (H. ${ }^{23} / 1$ ). Hovslund har 4 Mill. Pd. (H. ${ }^{11} / 10$ ). Hjerting 6,077,000 Pd. mod $4,855,000$ i 1923 (II. $7 / 11$ ). Møgeltønder steg med $28 \%$, Vilstrup med 10,4, hele Sonderjylland med $6-7 \%$ (L. S. 12).

Rømø Mejeri har bestaaet i 25 Aar (H. $\left.{ }^{24} / \tau\right)$, Broballe i

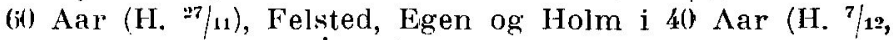
:1/12), Bevtoft 4) Aar (II. 1/s).

Under $K$ o n $t$ rol havde Fallesledelsen for rødt Kvæg i $26 / 27$ 10,737 køer, Fedtprocent var 3,56, (L. S. 33, H. 13/2). I Sønderborg Amt er 50\% af Køerne under Kontrol. Det er det jydske $\Lambda$ mt, cler er nærmest ved Fyn, som har $54,2 \%$. (L. S. 67). I Haderslev Amt er 38, i Aabenraa 24,1, i Sønderborg 47,9, i Tønder 9,5, i hele Jylland $25 \%$ under Kontrol (H. ${ }^{15} / 12$ ). I Hjerting Kontrolforening har Koerne ${ }^{27} / 28$ givet $149 \mathrm{~kg}$ Smør gennemsnitlig (H. $7 / \mathrm{s}$ ).

Det første M a l ke k u r s s i Sønderjylland afholdtes i Jiegerup Mejerikreds med 17 Deltagere (II. ${ }^{24} / 1$ ). Et følgende afholdtes paa Rønhave (H. $\left.{ }^{25}, 1\right)$.

Sønderjylland $\mathrm{S}$ møreks portforening omsatte 75,400 Dritler for $9 \frac{1}{2}$ M'ill. Kr. (H. ${ }^{23 / 10}$ ), den i Sønderborg 2,6017,510 kg (H. $\left.{ }^{31} / 10\right)$, dell i Haderslev 21,2013 Dritler og en Del Pakker (H. "/11).

Graasten A n d els s l a g t e ri slagtede 54,026 Svin (II. $5 / 1$ ). Det skal udvides (11. ${ }^{25} / 10$ ). Aabenraa 68,814, Bylderup-Bov 24,614 (Av. ${ }^{15}, 3$ ), Vojens 31,294 (II. ${ }^{15} / 3$ ), Skærbæk 23,551 (H. ${ }^{16} / 3$ ), Rødding 27,032 (H. ${ }^{18} / 2$ ), Sønderborg 82,315 heraf dog kun 39,220 er Andelssvin (H. ${ }^{27}$ og ${ }^{29} / 2$ ), Tønder Slagteri $25,151 \mathrm{Svin}\left(\Lambda \mathrm{v} .{ }^{18} / 3\right)$. 
Haderslev Amt havde 1927 20 Svineavlscentre (H. "/8). I I.sgumkloster og Omegn maatte Kartofielbroksparringen opretholdes (H. ${ }^{12} / 1$ ).

Sukkeroearealet tog af $\left(\mathrm{H} .{ }^{30} / 4\right)$.

I det kolde Foraar frøs mange hreaturer ihjel (II. $\left.{ }^{11} / 5\right)$, og Sandflugt hargede Markerne paa de magle Egne (II. ${ }^{2 * 2} 3$ ).

Ved Tonder maatte man endnu en (iang bjerge Harre fra Baad (H. $\left.{ }^{10} 11\right)$. IIøstudbyttet var 1920 og 1927 betyrleligt mindre end 1925). (H. $5 / 3$ ).

Paa $R ø m$ o drives endnu sad megen $F$ a a $r$ a $v l$, at der derfra kan sarlges et betyleligt Antal Lam (II. ${ }^{1 *}{ }^{*}$ ).

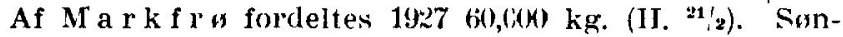
derjyllands Froforsynings Regnskab bylancerede metl $3\left(18,458 \mathrm{Kr}\right.$. $\left(H .{ }^{27} / 10\right)$. Planteavlsarbejdet er i rivencle $\mathrm{L}^{\top} \mathrm{ll}$ vikling (H. $\left.{ }^{1: 2}, 2\right)$.

Ved et I usma ndskursus i Aabenraa droftedes Undervisningen af de unge: (1J. ${ }^{3}{ }_{1}^{1}$ ). IIans Hansen finder, at Husmandene er i Fremgang. (H. ${ }^{4} 1$ ).

Aftenskole for unge Landbrugere har i Roclding varet holdt i :3 Aar og haft 250 Elever. Nu ogsaa i Byerne omkring Ihodling. (I1. A. " "2).

IIollandsk M a l kekvap viser $43 \mathrm{~kg}$ Malk og $0,9 \mathrm{~kg}$ Smar lremgang pr. Ko. (II. ${ }^{14 / 3}$ ). Llarlerslev F k s portstalde har haft 10,483 st. Kveag. (H. ${ }^{21}$ '). (I ksebremsen gar endnu stor skade her nede (II. ${ }^{2 *} / 3$ ).

li $\mathrm{j}$ ar l pen til Landlumet er meget stmpe Nord end Syd for (iræusent. (II. $\left.{ }^{1+} / \theta\right)$ ).

\section{b. Industri og Håndværk.}

Elektricitetsforsyningen ulvikles stadig mere. IIsjspandingsvarket i Aabenran har nasten fordoblet sin Produktion siden 18 , (H. ${ }^{9}$ s). Det er verl at blive for lille. (II. $\left.{ }^{24} ; 2\right)$. Det drafter Samarbejole med Aarhus $(H$. ${ }^{20} / 2$ ) og sixtter det i Vark med Flensborg (H. " ${ }^{24}$ \%). Narnlig Landbruget bruger megen Kraft. (H. $\left.{ }^{35} / \mathbf{s}\right)$. Hojsparndingsvirrket leverer Strum til IIaderslev Nies. (II. $\left.{ }^{30}, 1,{ }^{24}, 2\right)$. Ogsaa i Tyrstrup Herred (II. ${ }^{31}$ s), Sonclerborg og Aahen-

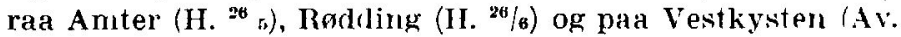
14/6) stiger Forbruget.

Aktieselskabet ll a nsborgs legnskab er lidt hedre end i Fjor ( $\mathrm{H}_{0}{ }^{31}{ }^{\prime}$ ). Aktiebryggeri og Margarinefabrik i Tonder giver $5 \%$ (tobytte. (II. "3/2). Orgelfabrikken $i$ 
Aabenraa leverer Orgler til Esbjerg, København og Odense $\left(H .{ }^{16} / 10\right)$, men af Teglværkerne ved Flensborg Fjord er ca. 20 bleven nedlugt (H. $\left.{ }^{10} / 10\right)$.

\section{e) Handel og Skibsfart.}

skibsfarten led en Del under Isvanskeligheder (H. ${ }^{4}$ og $5 / 1$ ). Graasten H a v n blev i 1927 anløben af 1702 Skibe. Ier udskibedes 20,000 Kreaturer fra den. (H. $/ 1$ ). Augustenborg af 521 Skibe. (H. $\left.{ }^{11} / 1\right)$. Sønderborg af 4,015, Aabenrau af 1,581, Haderslev af 2,515. (H. ${ }^{8} / 3,8 / 3,7 / 4,{ }^{25} / 1$ ). Tønder arbejder for at faa en Havn ved Lægan (H. ${ }^{25} / \mathbf{6}$ ). Den vilde dog komme til at koste 2 Mill. Kंr. (If. ${ }^{18} / \theta$ ). Ved Aabenraa Havn lagger det danske Gødningskompagni en Filial (H. $\left.{ }^{18} / 4\right)$, der indrettes en $B$ ananmodningsanstalt (H. $\left.{ }^{5 / 10}\right)$, og Flyverhallen omdannes til Eks portistalde. (H. $1 / 10$ og $\left.{ }^{18} / 10\right)$.

Ogsaa $F$ is k e riet udvikledes videre. Der tænkes indplantet 1 Mill. Rødspætter aarlig til Bælthavet $(\mathbf{H}$. $6 / 1,5 / 5)$. I Labenraa dannedes en Fiskeriforening $(\mathbf{H}$. $\left.{ }^{13} \mathrm{og}{ }^{16} / 1,7 / \mathrm{s}\right)$, Fiskerne omkring Aabenraa Fjord fangede fra ${ }^{14}{ }_{25} / 100,000 \mathrm{~kg}$ Sild. (H. ${ }^{27} / 1,{ }^{8} / 2,{ }^{13} / 2,{ }^{16} / 2$ ). Notfiskeriet skal være ødelæggende for de lokale Fiskere $\left(\mathrm{H} .{ }^{30} / 1\right)$. I Sommertiden var Fiskeriet fra Aabenraa sløjt. (H. ${ }^{24} / \mathrm{s}$ ).

Priserne paa Brød, Smør og Kalvekød var høje helnede (H. $\left.{ }^{15} / \mathrm{s}\right)$. De var gennemsnitlig $10-20 \%$ dyrere end $i$ andre dallske Provinsbyer (H. ${ }^{3 / 8}$ ).

\section{d) Pengevasen.}

Sønderjyllands $\mathrm{K}$ reditforening har i sidste Aar bevilget 502 Laan til $7,380,9010 \mathrm{Kr}$. $\quad(\mathbf{H} . \% / 10)$. Dens Balance er $173,614,680 \mathrm{Kr}$. Restancerne er fra 72,000 gaaet ned til 32,000 . (H. ${ }^{22} / 10$ ). Den tilbagebetaler et Statstilskud til Staten paa $50,\left(100 \mathrm{Kr}\right.$. (H. ${ }^{7} / 5$ ). Fn 4. Serie faar Statsgaranti (H. $11 / 1,{ }^{19} / 1,16 / 2,{ }^{25} / 2$ ).

Seks sønderjydske B a n ker indmeldte sig i Danske Provinsbankers Forening. (II. ${ }^{2: / 4}$ ). Sonderjydske Banker tegner 50,000 Kr. til Støtte for Ordningen af Privatbanken. (H. $\left.{ }^{2} / 10\right)$. Alle Bankers Beretninger giver Indtryk af voksende Virksomhed (II. $1 / 2,{ }^{8} / 2,1 / 3,{ }^{3} / 3,10 / 3,12 / 3,17 / 3,19 / 3,{ }^{21} / 3$; Av. ${ }^{7} / 2,2 / 3,{ }^{21} / 3$ ). Kun "Nordslesvigs Bank" maatte likvidere $\left(\mathrm{H} .{ }^{\mathrm{e}} / \mathrm{o}\right)$. Tyske Blade gav med Urette Bankinspektøren skyld for det (H. $\left.{ }^{1 \%} / 6\right)$. Den havde trærtimod ved Standsningen dobbelt saa mange danske Statsmidler, 
som Sønderjyllands danske Banker tilsammen (H. ' 7 ).

En ny Spare kasse oprettes i Tinglev. (II. ${ }^{15 / 2}, 2 / 10$ ). (Ogsaa Sparekassernes Beretninger lyder gunstigt (H. ${ }^{6} \mathrm{~s}$, ${ }^{11} / \mathrm{s}$, Av. ${ }^{21} / 2$ ).

Indskuddene i haade Banker og Sparekasser viser voksende Op s pa r ing. De er fra 1921-26 vokset fra 88,5 til 93,4 Mill. (H. ${ }^{19} / 3,8 / 0$ ), og de vokser stadig (II. ${ }^{10} / 1,23 / 1,6 / k$, $11 / 8,5 / 8$, Av. $\left.{ }^{16} / 10\right)$.

Landevaret har kun 1/o af sine Laan anbragt $i$ Ejendommene paa over 50 , (Kh) Kr. Fijendomsskyld. (II. ${ }^{13} / 1$ ). Det samlede i det første Aar $21 / 4$.lill, ordnede 510 Laan og medvirkede ved 92 andre Sager. $9(0,(4)(0) \mathrm{Kr}$. er anvendt i Grænseomradet (H. $\left.{ }^{23} / 1\right)$.

For yderligere at komme de nodstedte til $11 \mathrm{j}$; $1 \mathrm{p}$, blev der nedsat et Lidvalg. (II. ${ }^{28 / 3},{ }^{31 / 3} / 3,18 / 4,19 / 4,5 / 5$ ). Fra flere Sider kravedes standsning af Trangsauktioneme (H. ${ }^{21 / 4}$ ), hvad der ikke er muligt $\left(\mathrm{H} .{ }^{23} / 4,{ }^{24} / 4\right)$. Der afholdJtes i 1927 Tvangsauktion over $13,60^{\circ}$ no af Itndejendomme i Nordslesvig mod 4,5 ${ }^{\circ}$ no $\mathrm{i}$ det ovrige Land $\left(\mathrm{H} .{ }^{20} / 4\right)$. I de 3 Aar 1926-28 har der vir $5 \times 9$ Tvangsauktioner, deraf 328 over Landejendomme. Af de $5 \times 9$ var 59 Slagtsejendomme. De ovrige er der hundlet med siden 1910, de fleste efter Krigen (II. ${ }^{26} / 8$ ).

Vog elg es ang har fra ${ }^{1}: 27-31 / 328$ ydet $34 \tau$ Laan paa $2,366,354 \mathrm{Kr}$. Af kapitalen falder $75 \%$ i Granseomraadet (II. ${ }^{2 / 4}$ ). Til ${ }^{31}, 28$ steg hans Laaneantal til 4tii (II. $\left.{ }^{31} 110\right)$.

I, a a ne a as e n udlante $8,113,5,0) \mathrm{Kr}$. (H. ${ }^{13 / \mathrm{s}}$ ).

H y potek la a nefonden havde til Begyndelsen af April afgivet 1333 Laanetilbud paa godt 91/4 Mill. Kr. og udbetalt ca. (61/2 Mill. paa 917 Laan $\left(H .{ }^{10 / 4}\right)$. Sidst i Oktober var Laaneantallene 1364, summen 9,327,890 $\mathrm{Kr}$. (II. $\left.{ }^{29}, 10,30 / 10\right)$.

Sønderjydsk Fond har ialt anvendt 101/2 Mill. til Hjaplp (H. $3 / \mathrm{s}$ ).

Hafnia domtes til at hetale en Forsikring efter $(0 \mathrm{p}$ skrivningsprincippet (II. ${ }^{25 / 1}$ ). Efter det bliver en formue, der her mad vare bleven reguleret til 10,060) Kr. til 103 R. M. 85 Pf. (II. ${ }^{22} / 8$ ).

Haderslev Vesteramts Driftsla a neforening har 80 Laantagere med en (rarantikapital af $35,650 \mathrm{Kr}$. (II. $/ 8,2 / 7$ ). Her oprettes en for Haderslev og Omegn (H. $20 / 8$ ) og en for Tinglev og Omegn (II. ${ }^{10 / 7}$ ). 
Sydfor Gransen er Gx I den 518 M. 96 Pf. pr. ha, Rentefoden $9,13 \%$ (H. ${ }^{7}{ }^{7}$ ).

Motorsk a t ten er for Sønderjylland $454,788 \mathrm{Kr}$. (II. $5 / 10,10 / 10$ ).

Skatten resterer i mange Sogne, dog mest som Folge af for sløj Opkrerning. R e n t e rne indgar godt nok. (H. ${ }^{30}{ }_{13}^{\prime}$ ).

\section{e. Samkvem.}

Paa Strakningen Padborg-Fredericia kører nu Danmarks hurtigste Eksprestog $\left(\mathrm{H},{ }^{18 / 6}\right)$. Paa den ny L.ogumklosterbane er Færdselen starkt stigende (H. 1/2). Tønder -Iløjer-Banen gaar over til Motordrift (II. ${ }^{7} / 7$ ).

Sma abanerne kimper haardt for Tilvarelsen. Bedst stillet er de paa Mls. De kan vare gældfri om 20 Aar (H. $\left.{ }^{12} / \mathrm{s}\right)$. Godsmarngden stiger. Der befordres 467,0$)$ Personer (H. ${ }^{16 / 4}$ ). De gav sidste Aar $53,656 \mathrm{Kr}$. i Overskud (11. $\left.{ }^{28} / 6\right)$, men der gaar lige sad meget fods uden om dem som med dem (II. "5/10). Haderslev Amtsbaner har stort Underskud, men dog ca 1(0),0(0) mindre end i Fjor, da det var 467, , Uro Kr. (H., 11/9). De har kostet $12 \mathrm{Mill}$. Kl: at bygge og 1,2 Mill. Kroner at gøre i Stand, de har atrlig befordret 8-900,00(0) Mennesker, 150-1(ii),010) Tons (xods og ca. 40,(100 levende Dyr. (II. " $/ 7$ ).

Paa $V$ e je n e er der siden (ienforeningen anvendt $i$ Iaclerslev Amt $8\left(17,2\left(i 4 \mathrm{Kr}^{2}\right.\right.$, i Aabenraa 689,134, i Sønderborg 519,177 og i Tønder Amt 737,329 Kr. (H..21/6). Vejen Røalding-Foldingbro blev gjort fardig (H. ${ }^{13} / 10$ ), ligeledes Vejen fra Aabenraa Sønderchausse til Tønder Lanclevej (I1. ${ }^{15} / 11$ ). Tønder-Haderslevvejen tages i Udsigt (H. ${ }^{22 / 11}$ ). Den føres over Oksgaard (H. ${ }^{14} / 12$ ).

Trafikken til Røma er i de senere $A$ ar vokset starkt (H. ${ }^{24} / \mathrm{s}$ ).

Haderslev Amtsraad standser flere Bilruter (H. 27/11). Sønderborg $\Lambda$ mtsraad ønsker ingen nerlagt (II. ${ }^{4} / 12$ ).

Telefontaksterne mellem Nord- og Sydslesvig blev nedsat 1. 4. (H. ${ }^{24} / 3$ ). Padborg faar automatisk Telefoncentral (H. ${ }^{24} / 2$ ).

I Flensborg. blev bygget en Radiostation med gransepolitiske Formaal (H. :1/1). Der krævedes som Følge deraf stirkt en dansk Station i Nordslesvig. (H. ${ }^{3 / 1}$, $20 / 1,23,1)$. 


\section{Kommunalt.}

Skat teprocenten gik flere Steder ned. I IJaderslev fra 8,4 til 8,1 (II. ${ }^{15} 3$ ), i Tønder fra 11,6 til 10,(i) (H. $\left.24 / 3, \Delta v \cdot{ }^{23} / 3\right)$. I Aabenrad nedsattes Skattebelobet med $51,(00)$, men skatteprocenten blev den samme, 8,5 (H. ${ }^{24 / 3}$, 29/3). I sinderborg derimod gik den starkt op: fra 9,8 til 12,4 (II. ${ }^{17}$ s) og i Longumkloster fra $x, 1$ til 8,4 (II. ${ }^{92} / 3$ ).

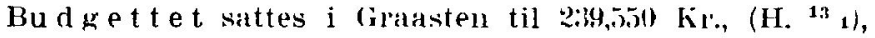

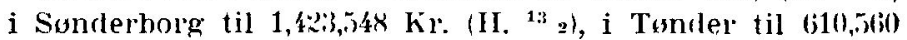
Kr. (II. ${ }^{17}{ }^{2}$ ).

De kommunale V ir $\mathrm{r}$ e r i Aabenra forrentede i Fjor Byens og Ilarnens (rald, 4,107,431 Kr., og gav desuden $135,574 \mathrm{kr}$. Overskul (II, ${ }^{25}$ 1). I Haderslev gav de 113,979 Kr. stome Overskud end ventet (II. ${ }^{1}$ *). I Aabenrata blev

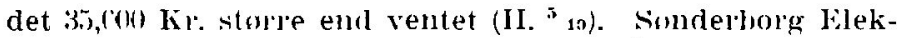
tricitetsrark gav o8,246 Kr., Gaswarket 29,9993 hr. Overskud (H. " s). I Haderslev blay Ingenior Andersen fra liurup Direktor' for Varkerne (II. 'i1).

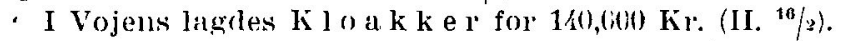

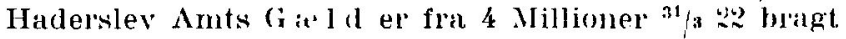
nerl til $2, x$ Mrill. ${ }^{1}, 3 x$ (II. ${ }^{13}{ }^{\prime} 3$ ).

Ved $A m \mathrm{msra}$ a d s valge ne vault i Harlerslev so cialdenukraterne et Manclat fra de radikale (II. ${ }^{24}$ \%). I Aabenraa valgtes 8 danske, 2 socialdemokmaler og $1 \mathrm{Ty}$ sker (H. $\left.{ }^{1 N}{ }_{4}\right)$, i Tunder 11 danske, 1 Socialdemokrat og 1 Tysker (II. ${ }^{\text {th }}$ ), i Sond Phorg 9 horgerlige og 2 socialde mokrater. (II. "2is).

\section{Menighedsliv.}

Til Fuldforelse af Restaureringen af Kirken $i \mathrm{La}$

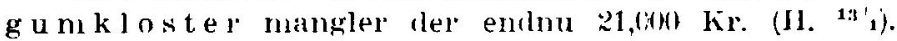
Der holdtes i 19:2 liz danske fudstjenester i den med ratio Kirkegarngere og (bix Altelgarster, 15 tyske med henholdsvis $($ is) $\log 30(11.4 / 1)$.

Striden om Fol hirke endte for Hwjesterel med det Resultat, at (irev Brockenhuus-Schack skal beholde den (H. $4 / 1,{ }_{1}$ ), (ireven overdroy den derefter til Menighedsradet ow betalte $16,5 \% \mathrm{Kr}$. I Iffindelse og thon til Iieparation (H. ${ }^{14}$ 21.

Pastor Tommesen fortsulter efter sin Afgang med at foretage de kilkelige Hamllinger i Hoptrup, Vilstrup og Vedsted siogne, der forlanges udfort paa Tysk (H. ${ }^{2}$ 1). Bov Sogn tankes delt (II. "'i). I'astor Bjery flytter fra Skod- 
borg (II. ${ }^{6 / 2}$ ). Pastor Max Mathiesen fra Haderslev rejser til Kanada (11. 's). Pastor Frederiksen udnavntes til Kajnæs (H. $\left.{ }^{10} / 4\right)$. Pastor Brondherg til IInspitalsprast i Haderslev $($ H. $3 / 0$ ).

Præistega ardene er nu afleveret, og der kan ikke ydes noget kontant Tilskud til dem $\left(\right.$ H. $\left.{ }^{20} / 1,{ }^{27} / 1\right)$. Derimod vil Ministeren søge at gennemføre, at Tilsvaret af Præstegaardsjortlerne ydes i horn. (H. " $/ 2$ ). Et Forslag om Tiende a f los in $\mathrm{l}$ inder Tilslutning (H. $7 / 3,{ }^{18} / 3$ ). De tyske Fremmedmenigheder agiterer for Masseudtradelse af Folkekirken $\left({ }^{22} i_{i,}{ }^{20} i_{i \theta}\right)$. Storre ki rkelige Møder holdtes i Rodding (Frimenighed) (H. ${ }^{\text {' }}$ ), Kristiansfeld (H. ${ }^{21}$ s), Rothling (H. ${ }^{20}{ }_{s}$ ) og Vedsted (H. $\left.1 / g\right)$.

\section{Oplysning.}

I IIaderslev er Antallet af danske Elever det samme som i lijor, 196 , det $t y<k e ~ t$ mindre, 70 (H. A. ${ }^{16} / 1$ ). For 1929 er indmeldt 191 danske og 93 tyske (H. ${ }^{11}{ }_{11}$ ). Der var i det hele 1739 Børn i Skolerne, deraf 13012 i de dansksprogede (H. ${ }^{23}$ 's, Beretning om Skolevasenet i Haderslev 1928). I Sonderborg Ant havde Skoleme t502 Børn, deraf . 3955 i danske Afdelinger, desuden 60 i tyske og 91 i danske Privatskoler $\left(I I,{ }^{"} / 3\right)$ ). I Tonder $\Lambda \mathrm{mt}$ er der 81 danske og 9 tyske Folkeskoler, 4757 Børn (deraf $49 \%$ i tyske) mod 6551 i 1921. Af de 4757 gaar 211$)$ i Privatskoler $(130$ d., 80 t.). I Tonder By gaar 372 i danske og 379 i tyske Skoler (H. ${ }^{3 / 4}, \Delta v .{ }^{3}{ }^{4}$ ). I den danske skole $i$ Tonder er indmeldt 66. Antallet er starlig stigende (Av. ${ }^{10}$ 's). I Aabenraa Amt - er der 4:370 i danske og 753 i tyske skoler. Det samlede Borneantal er steget med 10:3 (If. $\left.{ }^{14}, 4\right)$. Af de 106 skoler i Haderslev Amt er de 104 dansksprogedle med 7008 Børn, de to tyskinrogede har 43\%. 14\%4 i dansksprogede Skoler har deltaget i tysk Undervisning. (IH. " a Folkeskolen i Haderslev Amt 192\%).

Om gejstligt Tilsyn med Skolerne voldte Menighedsratisforeningen en lang strid. (H. ${ }^{13}{ }_{2}$ o. f. $\left.{ }^{3 /}\right)_{3},{ }^{27} / \mathrm{s}$, $\left.{ }^{30} \mathrm{og}{ }^{31}{ }_{5,}{ }^{36}{ }^{6}\right)$ der dog ikke forte til noget. (II. ${ }^{27}{ }_{3}$ ).

Fra Tonder s' e mo i n a r udgik 27 (H. ${ }^{18} / 6$ ) fra Haderslev 30 Elever (H. $\left.{ }^{21 / 6}\right)$.

Danebod H o j s kole har ${ }^{2 \pi}{ }_{2 \$}$ haft 131 Elever. Den or i stadig Stigen (II. ${ }^{25} / 6$ ).

Aabenraa Statsskole havde $2(4 ;$ Elever. (H. $7 / 6)$. Fra Sonderborg har :0 taget Studentereksamen. (H. ${ }^{20} \%$ ). 
Fra Haderslev $27 .\left(H_{0}{ }^{2 H}{ }_{8}\right) . \quad$ Fra Twmder 10. $\left(H .{ }^{20} / 8\right)$. Fra Aabenraa 11. (H. ${ }^{24 / 6}$ ).

I Løjt tænktes en Realskole oprettet. Den tysksinclede Formand for Skolekommissionen modarbejdede imidlertid Planen. (H. $\left.{ }^{11} / 1\right)$. Tinglev Realskole faar foruden de 35,000 et nyt Statslaan paa 10,0100 Kr. (H. ${ }^{18} / 1$ ). Til ny Bestyrer fik den Fallesen fra Langaa (H. ${ }^{30} / 5$ ).

De tyske skolekrav var stalig uafgjort. Der krives et rent Afslag. (H. $\left.{ }^{14} / 1,{ }^{18} /{ }_{1},{ }^{20},{ }_{1},{ }^{21} / 1\right)$. Formaalet med dem er at uddanne tyske Førere (H. ${ }^{21} / 1$ ). Omsider fik de Afslag (H. ${ }^{24} / 1$ ). Utilfreds med det, agter den tyske Skoleforening i Tinglev at stille nyt Anrlragende til Folketinget $\left(\mathrm{H}^{\mathrm{y} / 2}\right)$.

Ldvidelserne af $\mathrm{Folkeskolel}$ lne i Iladerslev har kostet $600,000 \mathrm{Kr}$. Hertug Hans Skolens Gymnastik- og Sløjdsal har alene kostet 110,000 . (II. A. ${ }^{18}$ /).

Haderslev Central bibli ote $k$ fik ny Lokaler indrettet. (H. ${ }^{23}$ 1). Biblioteket i Tønder har udlaant 36,537 Bind 1il 140) Laanere, hvoraf de 1200 er fra Tonder (H. ${ }^{13} / 3,{ }^{12} / 5$, Av. $\left.{ }^{10} / 5\right)$. Sønclerborg hal over 13,000 Bøger, det har udlaant 62,(334. (H. ${ }^{11} / 5$, Av. ${ }^{5 / 4}$ ). Landsbiblioteket har 20,190 Bind. Det har udlaant 64,745 til 2662. (H. ${ }^{14}$ 's). Statstilskuddet var $^{24} / 2075,651 \mathrm{Kr}$. (H. ${ }^{16}{ }^{*}$ ). Til Fordeling mellem sønderj. Bihlioteker skænkerle Lektor Bloch Thrige en stor Del af sit Bibliotek. (H. \%/2).

En sønderjydsk Vandrebogsamling har 68 Abonnenter og 98 sat Buger a ca. 20 Eksemplarer. (II. ${ }^{13} / 6$ ).

IIi s t o risk s a m f und har (557 Niedlemmer.

\section{9.) Ret og Forvaltning.}

I Folketinget fremsiettes Forslag om Ophryelse af do sønderjydske $S$ i love. (I. ${ }^{10} / 10$ ). Af større Retstrætter kan nævnes en Formynderisag fl'a Mommark, hvor Overformynderiet solgte Chr. Paulsens Gaard. Der paastodes i et tysk Blad, at det var for billigt, og at det var sket uden Børnenes og Værgernes Vidende. (H. 1/2). Det viste sig, at der intet var at bebrejde Myndighederne i den Sag. ${ }^{27} / 2,{ }^{14} / 5,{ }^{10} / 5,{ }^{21} 5,{ }^{30} / 8,{ }^{11} / 8$ ).

Thomsen, Skovgarrd, fik ved Højesteret den ham i Fjor idømte Straf skærpet til tre Maaneders Fangsel paa sædvanlig Fangekost. (H. $\left.{ }^{11} / 1\right)$. Bossen fra Øster Højst idørtes $40 \mathrm{og}$ Thomsen fra Ellehus 20 Dages Fangsel for Vold mod Kongens Foged. $\left(\right.$ H. ${ }^{23}{ }^{3}$ ). For Del i en stor 
Forsikringssvindel i Haderslev stadfæstede Højesteret Dommen over Arbejder Hoffmann og Hustru: et Aars Forbedringshus og 60 Dages Fængsel. (H. ${ }^{27} / 1,20 / 3$ ). Højesteret stadfæster Dommen over Lærer Petersen fra Højer (60 Dages Fængsel) og flere andre. (H. $8 / 3,24 / 3$ ). Højesteret frifandt Sønderborg for Valsemøllens Erstatningskrav, 1918 Kr. (H. \%).

Sogneraadsformanden beskyldes for at have bedraget Staten og Rømø Kalkforbund for 165 Tons Kalk. (H. ${ }^{10 / 8}$, Av. ${ }^{19} / 8$ ). Kalken blev senere skaffet tilveje. (Av. ${ }^{5} / \%$ ).

Ved en Tvangsauktion til 11,000 løb Omkostninge rne op til 625 Kr. 20 Øre. (H. ${ }^{11 / 7}$ ).

\section{Pressen.}

Dybbølposten kan fejre 60 Aars Jubilæum. (II. ${ }^{7 / 1}$ ). "Apenrader Tageblatt" og "Neue Tondernsche Zeitung" slaas sammen. "Sonderburger Zeitung" vil ikke med (H. $2 / 2$ ). "Modersmaalet" har 15,373 Kr. Overskud (H. ${ }^{13} / 3$ ). "Hejmdal" holdt Generalforsamling ${ }^{31 / 5 .}$ (H. 1/a). Selvstyrebladet standser den $1 / 7$. (H. $\left.{ }^{8 / 6},{ }^{12} / 8\right)$. Leifolkene prøvede at faa Folk til at afsige danske Blade (H. ${ }^{26} / \mathrm{s}$ ), men forgæves (H. $\left.{ }^{4 / 7}\right)$.

\section{Personligt.}

Kasper Jensen, Broager, blev 70 Aar ${ }^{13} / \mathrm{s}$, (H. ${ }^{11} / \mathrm{s}$ ), H. J. Jefsen, Skærbæk, 60 Aar ${ }^{19} / 8$, (H. ${ }^{17} / 8$ ), Magnus Schmidt fra Rødding har gjort en betydningsfuld kemisk Opdagelse. (H. ${ }^{18} / 12$ ).

Blandt dem, der d ø d e i 1928 nævnes Marie Andresen, Ullerup, (H. ${ }^{13} / 1$ ), Lærer P. Møller, Aabenraa, (H. $\left.{ }^{27} / 1\right)$, Erich Schlajkjer, Berlin, (H. $\left.{ }^{13} / 2\right)$, Andreas Blad, Augustenborg, (H. ${ }^{16} / 2$ ), Grosserer Johan Hansen i Charlottenlund, (H. ${ }^{2 \pi} / 2$ ), Forfatteren Jens Skytte i Kolding, (H. ${ }^{28} / 2$ ), Forfatterinden Martha Ottosen (H. 1/3), Pastor W. v. Brincken i Ribe, (H. $\left.{ }^{12} / 4\right)$, Redaktør P. Eliassen, Kolding, (H. 8/5), Bankdirektør Rossen, Tønder, (H. $\left.{ }^{15} / \mathrm{s}\right)$, Gartner P. Jensen, Tombøl, (H. $\%$ ), v. Köller, (H. $\left.{ }^{13} / 12\right)$, Kniplerske Lisette Dyrberg, Rørkær, (H. ${ }^{18 / 12}$ ).

\section{Andre Sager.}

Hejmdal offentliggør ${ }^{25} / 1$ ff. en Række Akter fra den tyske Tid. 
Staten køber Skoven ved Rønshoved. (H. 4/2). Paa Rømø har man faaet Husrotter efter at Vandrotterne er fordrevne. (H. ${ }^{15} / 3$ ). En tysk Landbrugskonsulent roser Bondelandet Danmark. (H. ${ }^{4 / 6}$ ). Hugo Matthiesen mener; at Tingstedet har været paa Urnehoved. (H. $7 / 8$ ). I Aaben' raa Amt er mange Punkter fredet. (H. ${ }^{22} / \mathrm{s}$ ). I Danmark. er ialt oprettet 13,100 Husmandsbrug. $\left(\right.$ H. $\left.{ }^{17} / 2\right)$. Det frivillige Brandværn i Aabenraa har bestaaet i 50 Aar. (H. ${ }^{30} / 7$ ). 